\title{
Respiratory failure caused by a traffic accident successfully treated with ECMO - Case report a review of the literature
}

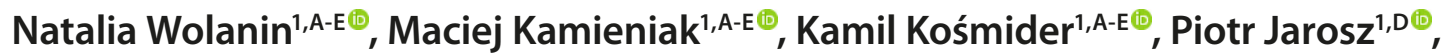 \\ Michał Borys ${ }^{2, E-F}$ (i) \\ ${ }^{1}$ Student's Scientific Association, II Department of Anaesthesiology and Intensive Care, Medical University, Lublin, Poland \\ 2 II Department of Anaesthesiology and Intensive Care, Medical University, Lublin, Poland \\ A - Research concept and design, B - Collection and/or assembly of data, C - Data analysis and interpretation, \\ $D$ - Writing the article, E - Critical revision of the article, F - Final approval of article \\ Wolanin N, Kamieniak M, Kośmider K, Jarosz P, Borys M. Respiratory failure caused by a traffic accident successfully treated with ECMO. \\ A case report a review of the literature. J Pre-Clin Clin Res. 2020; 14(1): 8-10. doi: 10.26444/jpccr/118446
}

\begin{abstract}
Introduction. Acute respiratory distress syndrome is an inflammatory process that results in impaired lung function. It is predicted that by 2025 , it will be the third largest cause of death. In some cases, extracorporeal membrane oxygenation may be the last option, improving patient outcome.

Case report. The study presents a case of successful treatment od 47-year-old man. Due to respiratory failure following trauma, veno-venous extracorporeal membrane oxygenation therapy was initiated. Systemic anticoagulation with unfractionated heparin was not used in this case. A prophylactic dose of low molecular weight heparin was administered instead. After stabilization of the vital signs, the patient was discharged from the intensive care unit.

Conclusions. Extracorporeal membrane oxygenation might be a good option for patients suffering from severe acute respiratory distress syndrome, but protective ventilation is still a method of choice. There have been studies indicating patients outcome improvement; however mortality reduction is still elusive.
\end{abstract}

\section{Key words}

respiratory failure, acute respiratory distress syndrome, extracorporeal membrane oxygenation

\section{INTRODUCTION}

Acute respiratory distress syndrome (ARDS) is a rapid inflammatory process in the lungs, leading to pulmonary oedema with non-hydrostatic etiology, resulting in impaired lung function, hypoxia and reduced $\mathrm{CO}_{2}$ removal [1]. The occurrence ranges from 7-59 per 100,000 patients, and the mortality is up to $40 \%$ [2]. According to the World Health Organization (WHO) data, by 2025, ARDS may become the third largest cause of death [2]. According to the Berlin definition, several criteria should be met to recognize ARDS (Tab. 1) [3]. The study conducted in 50 countries showed that among ICU patients, ARDS is evolving in $10.4 \%$ of hospitalized patients; however, this syndrome is underrecognized. Mild ARDS represents $30.0 \%$ of all cases; moderate $46.6 \%$; and severe, $23.4 \%$. Overall mortality among ARDS patients was higher in patients with more severe ARDS [4].

In some severe cases of ARDS, extracorporeal membrane oxygenation (ECMO) might be worth considering as a way of treatment in order to improve patient outcome. ECMO supports respiratory or/and circulatory systems in the case of their severe failure. The crucial criterion for the application of this method is the potential reversibility of the disease process responsible for the current state of the patient [5].

Two types of ECMO therapy are used in clinical practice: veno-venous (VV ECMO) methoid and veno-arterial

Address for correspondence: Natalia Wolanin, Student's Scientific Association, II Department of Anaesthesiology and Intensive Care, Medical University of Lublin, Poland

E-mail: natalia.wolanin@op.pl

Received:11.01. 2020; accepted: 25.02.2020; first published: 12.03 .2020
Table 1. ARDS Berlin Criteria [3]

\begin{tabular}{|c|c|}
\hline Onset & $\begin{array}{l}\text { Within } 7 \text { days from occurrence of known risk factor or new or } \\
\text { worsening respiratory symptoms. }\end{array}$ \\
\hline $\begin{array}{l}\text { Chest imaging } \\
\text { (RTG or CT) }\end{array}$ & $\begin{array}{l}\text { Bilateral opacities, which cannot be explained by effusions, } \\
\text { lobar/lung atelectasis or nodules }\end{array}$ \\
\hline Cause of edema & $\begin{array}{l}\text { Respiratory failure cannot be fully explained by heart failure } \\
\text { or fluid overload. If there are no risk factors, an objective } \\
\text { assessment (e.g. echocardiography) is necessary to exclude } \\
\text { hydrostatic edema. }\end{array}$ \\
\hline $\begin{array}{l}\text { Oxygenation } \\
\text { index }\end{array}$ & $\begin{array}{l}\text { Mild ARDS: } 200 \mathrm{mmHg}<\mathrm{PaO}_{2} / \mathrm{FiO}_{2} \leq 300 \mathrm{mmHg} \text { with PEEP or } \\
\text { CPAP } \geq 5 \mathrm{cmH}_{2} \mathrm{O} \\
\text { Moderate ARDS: } 100 \mathrm{mmHg}<\mathrm{PaO}_{2} / \mathrm{FiO}_{2} \leq 200 \mathrm{mmHg} \text { with } \\
\text { PEEP } \geq 5 \mathrm{cmH}_{2} \mathrm{O} \\
\text { Severe ARDS: } \mathrm{PaO}_{2} / \mathrm{FiO}_{2} \leq 100 \mathrm{mmHg} \text { with PEEP } \geq 5 \mathrm{cmH}_{2} \mathrm{O}\end{array}$ \\
\hline
\end{tabular}

The table describes the Berlin definition of ARDS. ARDS, acute respiratory distress syndrome; CPAP, continuous positive airway pressure; $C T$, computed tomography; PEEP, positive endexpiratory pressure.

(VA ECMO) method. The former is used in patients with respiratory failure and allows blood oxygenation and carbon dioxide removal. The latter (VA) is indicated in patients with cardiac failure [6]. The detailed indications and contraindications for VV-ECMO therapy are presented in Table 2.

The first randomized controlled trial concerning ECMO was published in 1979 [7], and over time a number of studies have elaborated on the subject; however, mortality reduction in patients with ARDS on ECMO is still elusive $[8,9,10,11]$.

The aim of the current study was to present a clinical case of successful treatment of the patient after a road accident on VV ECMO support. 
Table 2. Main indications and contraindications for VV ECMO therapy

\begin{tabular}{|c|c|}
\hline Indications & Contraindications \\
\hline \multirow{8}{*}{ 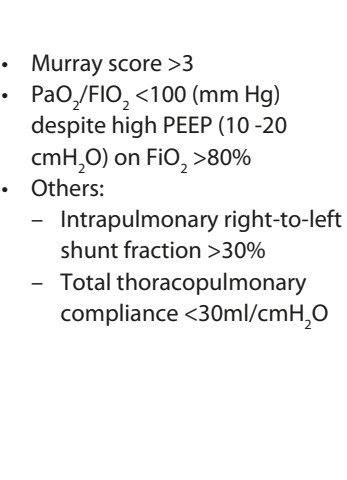 } & Absolute \\
\hline & - Irreversible cardiac or pulmonary disease \\
\hline & - Metastatic malignancy \\
\hline & - Significant brain injury \\
\hline & - Current intracranial hemorrhage \\
\hline & $\begin{array}{l}\text { - Major pharmacologic immunosuppression } \\
\text { (absolute neutrophil count }<400 \text { ) }\end{array}$ \\
\hline & Relative \\
\hline & $\begin{array}{l}\text { - Age }>65-70 \text { years, considering increasing } \\
\text { risk with increasing age } \\
\text { - } \text { Mechanical ventilation at high settings } \\
\left(\mathrm{FiO}_{2}>90 \% \text {, }\right. \\
\text { Plateau Pressure }>30)>7-10 \text { days } \\
\text {. } \text { Multi-trauma with high risk of bleeding }\end{array}$ \\
\hline
\end{tabular}

$\mathrm{FiO}_{2}$ - fraction of inspired oxygen; PEEP - positive end-expiratory pressure; VV ECMO - venovenous extracorporeal membrane oxygenation.

Source: Zangrillo A., 'The criteria of eligibility to the extracorporeal treatment.', in: HSR Proc ntensive Care Cardiovasc Anesth. 2012; 4(4): 271-273.]

\section{CASE REPORT}

A 47-year-old man was hospitalized in the surgical ward after a traffic accident that resulted in chest contusion, broken right clavicle and sternum. On the $2^{\text {nd }}$ day, due to severe respiratory failure, the patient was transferred to the Intensive Care Unit (ICU) where immediate intubation was performed. Clinical and radiographic features of $\mathrm{ARDS}\left(\mathrm{PaO}_{2} / \mathrm{FiO}_{2} \leq 100 \mathrm{mmHg}\right)$ were found. Pre-ECMO mechanical ventilation parameters were: $\mathrm{FiO}_{2}$ 100\%; PEEP $18 \mathrm{~cm} \mathrm{H} \mathrm{H}_{2} \mathrm{O}$, Vt $460 \mathrm{ml}$, f=24/min. In addition, the patient was prone due to trauma. After considering these circumstances, the decision to taken to carry out ECMO therapy. Cannulation of the femoral and the jugular veins was performed under ultrasound control, and VV ECMO therapy initiated with $3.5 \mathrm{~L} / \mathrm{min}$ of blood flow and $3 \mathrm{~L} / \mathrm{min}$ of oxygen (sweep gas). Importantly, systemic anti-coagulation with unfractionated heparin (UFH) was not used in this case. A prophylactic dose of low molecular weight heparin $(\mathrm{LMWH})$ was administered instead $(0.6 \mathrm{ml}$ of Fraxiparine s.c).

On the same day, because of oliguria and renal markers elevation, Continuous Renal Replacement Therapy (CRRT) was started. Creatine kinase was only slightly elevated (300 IU/L), calcium and potassium were within the normal range and mioglobinuria was not measured. Despite the low risk, acrush syndrome was suspected. Due to confirmed pneumoniabroad-spectrum antibiotics were implemented. In addition, norepinephrine infusion was started. Chest $\mathrm{X}$-ray revealed almost complete shading of the right lung and parenchymal density in the lower lobe of the left lung, as well as obliteration of the right hemidiaphragm. Mechanical ventilation with $\mathrm{FiO}_{2} 0.6$ and PEEP $12 \mathrm{~mm} \mathrm{Hg}$ was maintained. On the $3^{\text {rd }}$ day, percutaneous tracheostomy under bronchofiberoscopy control was performed, and bronchoalveolar lavage (BAL) obtained.

On the $4^{\text {th }}$ day of hospitalisation, X-ray showed the progression of changes in comparison to the previous pictures, described as the total shading of the lower and middle lung lobes (Fig. 1 and 2). From the $5^{\text {th }}$ day, the patient no longer required cardiac support with catecholamines, although CRRT, ECMO therapy, and mechanical ventilation were still required. The obtained BAL cultures showed the

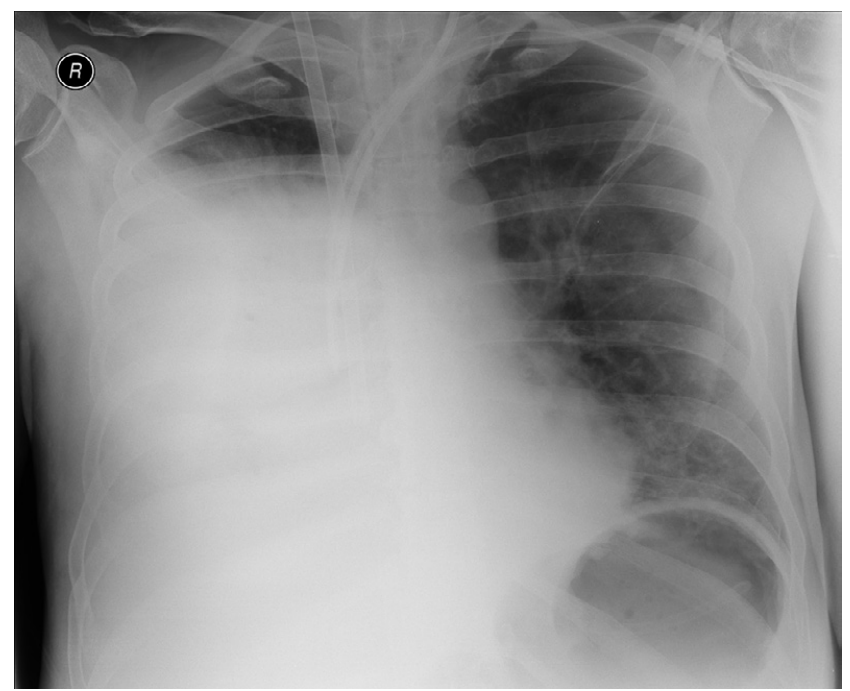

Figure 1. The chest $X$-ray on $1^{\text {st }}$ day

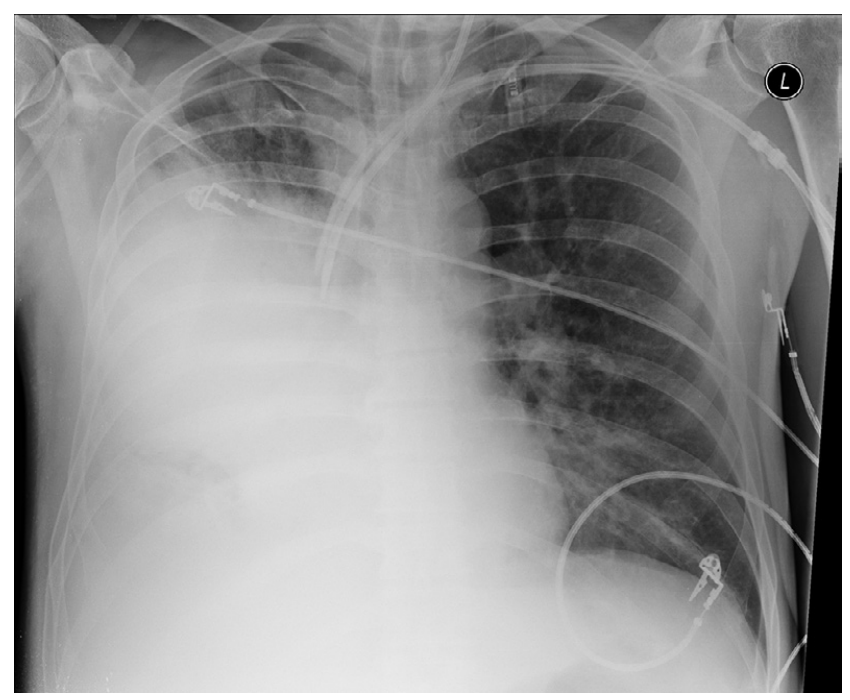

Figure 2. The chest X-ray on 4th day

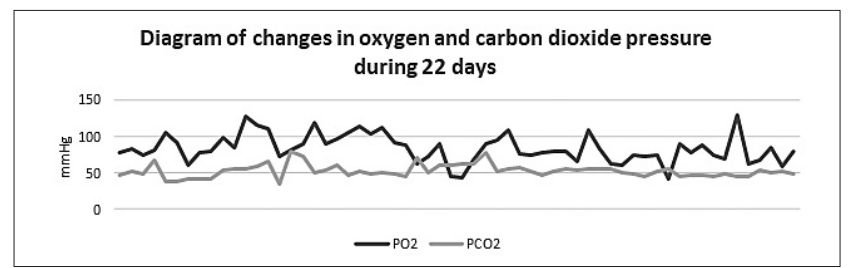

Figure 3. Arterial blood-gas pressures

The graph presents arterial pressures of oxygen and carbon dioxide variation during ECMO therapy and ICU stay

presence of Candida glabrata; therefore, micafungin was added.

ECMO therapy was completed on the 8th day with blood flow at $3.5 \mathrm{~L} / \mathrm{min}$, and sweep gas $1 / \mathrm{L}$ Decannulation proceeded without complications. Renal replacement therapy was continued and mechanical ventilation in CPAP mode with $\mathrm{FiO} 2$ of 0.5 , PEEP 8 was maintained in the following days. The patient repeatedly required toilet of the bronchial tree due to the large amount of mucopurulent secretion. Nutrition was given by the enteral route. The patient was extubated on the $20^{\text {th }}$ day. 
The patient survived and after stabilization of the vital signs, he was eventually discharged from the ICU to the ward on the $22^{\text {nd }}$ day.

\section{DISCUSSION}

Although lung protective ventilation, based on low tidal volume $(\leq 6 \mathrm{~mL} / \mathrm{kg})$ and driving pressure $\left(\leq 15 \mathrm{cmH}_{2} \mathrm{O}\right)$ is a method of choice when caring for patients with ARDS, in some severe cases, ECMO might be an option. The other problem presented in the current case concerned the anti-coagulation strategy during ECMO support. Although Extracorporeal Life Support Organization (ELSO) recommends continuous UFH administration during ECMO support, in this case, due to bleeding risk, LMWH given once daily which provided sufficient anti-coagulation.

There have been several studies proving the reduction of mortality among patients treated with this method; for instance, a study conducted on a group of 68 patients treated with ECMO in Australia and New Zealand revealed mortality rate at only $29 \%$ [8], while a similar study in the United Kingdom showed a mortality rate at $23.7 \%$ among patients treated with ECMO, compared to even $52.5 \%$ treated with different methods [9]. The results of treatment with ECMO in post-traumatic patients seem to be equally promising. For example, in one study, 16 out of 22 patients treated for respiratory failure survived (72.3\%) [10], while another retrospective cohort study performed on a larger number of patients showed the survival rate at $64 \%$ and survival to discharge at $55 \%$ [11].

\section{CONCLUSIONS}

Although the presented results seem to be promising, the outcome of the treatment will not be positive for every patient. Due to high costs as well as numerous potential complications, there is a need for accurate and reliable assessment of the patient in order to implement treatment.

Analysis of 2,355 patients in 2000 - 2012 conducted by the Extracorporeal Life Support Organization (ELSO) enabled the development of an estimated survival rate for ECMO patients [12]. The Respiratory Extracorporeal Membrane Oxygenation Survival Prediction (RESP) Score assesses risk factors, such as age, reasons for respiratory failure, medicines used, comorbidities, $\mathrm{PaCO}_{2}$ and peak inspiratory pressure, and assigns the patient to one of the risk classes. The patient described in the current study had 6 points on the RESP Score and classified him to the first risk class with an estimated chance of survival of $92 \%$.

Severe ARDS is characterized by a poor prognosis; nevertheless, many patients can be successfully treated with ECMO. Although ECMO does not cure the disease itself and can only support keeping the patient alive, many studies show a significant increase in survival rates of the patients undergoing this method, and therefore should be considered for any patient with severe ARDS, including post-traumatic lung failure.

\section{REFERENCES}

1. Rezoagli E, Fumagalli R, Bellani G. Definition and epidemiology of acute respiratory distress syndrome. Ann Transl Med. 2017; 5(14): 282.

2. Gattononi L, et al. The future of mechanical ventilation: lessons from the present and the past. Critical Care 2017; 21: 183.

3. The ARDS Definition Task Force. Acute Respiratory Distress Syndrome: The Berlin Definition JAMA. 2012; 307(23): 2526-2533.

4. Bellani G, Laffey J, Pham T, et al. Epidemiology, Patterns of Care, and Mortality for Patients with Acute Respiratory Distress Syndrome in Intensive Care Units in 50 Countries JAMA. 2016; 315(8): 788-800.

5. White A, Fan E. What is ECMO? Am J Respir Crit Care Med. March 2016; 193(6): 9-10.

6. Lafç G, Budak A, Yener A, Cicek O. Use of extracorporeal membrane oxygenation in adults. Crit Care Clin. October 2017; 33(4): 763-766.

7.Zapol W, Snider M, Hill J, et al. Extracorporeal membrane oxygenation in severe acute respiratory failure: a randomized prospective study JAMA. 1979; 242: 2193-2196.

8. The Australia and New Zealand Extracorporeal Membrane Oxygenation (ANZ ECMO) Influenza Investigators, „Extracorporeal Membrane Oxygenation for 2009 Influenza A(H1N1) Acute Respiratory Distress Syndrome" JAMA. 2009; 302(17): 1888-1895.

9. Noah M, Peek G, Finneu S. Referral to an Extracorporeal Membrane Oxygenation Center and Mortality Among Patients With Severe 2009 Influenza A(H1N1) JAMA. 2011; 306(15): 1659-1668.

10. Wu M, Chou P, Wu T, Lin P. Predictors of hospital mortality in adult trauma patients receiving extracorporeal membrane oxygenation for advanced life support: a retrospective cohort study. Scandinavian Journal of Trauma, Resuscitation and Emergency Medicine 2018; 26(14).

11. Grant A, Hart V, Lineen E, Lai C, Ginzburg E, Houghton D, Schulman C, Vianna R, Patel A, Casalenuovo A, Loebe M, Ghodsizad A. The Impact of an Advanced ECMO Program on Traumatically Injured Patients. Artif Organs November 2018; 42(11): 1043-1051.

12. Schmidt M, Bailey M, Sheldrake J, Hodgson C, Aubron C, Rycus P, Scheinkestel C, Cooper D, Brodie D, Pellegrino V, Combes A, Pilcher D. Predicting survival after extracorporeal membrane oxygenation for severe acute respiratory failure. The Respiratory Extracorporeal Membrane Oxygenation Survival Prediction (RESP) Score. Am J Respir Crit Care Med. 2014; 189: 1374-1382. 